\title{
Histología del ovario y ciclo reproductivo de Columbina picui (Temminck, 1813) (Aves: Columbidae) en Córdoba, Argentina
}

\author{
Ovarian histology and reproductive cycle of Columbina picui (Temminck,1813) \\ (Aves: Columbidae) from Córdoba, Argentina
}

\author{
Elsa Inés Altamirano ${ }^{1 *}$, Mirian Bulfon ${ }^{1}$ y Noemí Bee de Speroni ${ }^{1}$
}

\begin{abstract}
1Departamento de Diversidad Biológica y Ecología. Cátedra de Anlogica ycologia. Cater Anatomia Comparada. Facultad de Ciencias Exactas, Físicas y Naturales, Universidad Nacional de Córdoba. Avda. Vélez Sársfield 299, Córdoba CP - 5000. República Argentina. Email Mirian Bulfon: mbulfon@com.uncor.edu
\end{abstract}

Presentado: 09/01/2009 Aceptado: $11 / 05 / 2009$ Publicado online: 28/08/2009

\section{Resumen}

Con la finalidad de caracterizar el ciclo reproductivo anual de Columbina picui se realizó el análisis estructural y cuantitativo de los ovarios de ejemplares adultos recolectados entre los años 2005-2006 en la Sierra de Macha (Totoral, Córdoba, Argentina). Durante la fase de recrudescencia gonadal (junio a marzo), se determinaron tres valores máximos; el primero en junio, resultado de la ovipostura de las hembras subadultas (plumaje de adultos y vestigios de la Bursa de Fabricius); los restantes valores se registraron uno en septiembre y el otro en enero correspondiendo al de las hembras adultas. La regresión ovárica se inició a partir de la incubación de los huevos y el reposo gonadal de la mayoría de las aves entre abril y mayo. Se identificaron dos tipos atresia folicular: a) no bursting, la pared folicular se mantiene intacta, comprende a la lipoidal (ovocitos primordiales) y a la lipoglandular (folículos previtelogénicos y vitelogénicos pequeños), ambos procesos se visualizaron durante todo el ciclo reproductivo y b) bursting las paredes foliculares se rompen, afecta a los folículos vitelogénicos menores de $800 \mu \mathrm{m}$ y sólo fue detectada posterior a la ovipostura. El ciclo reproductivo de $C$. picui se caracterizo por alta frecuencia de hembras con capacidad de reproducirse durante la mayor parte del año y la prolongada fase de recrudescencia gonadal.

Palabras claves: Aves silvestres, torcacita, ciclo reproductivo, morfohistología.

\begin{abstract}
The annual reproductive cycle of Columbina picui was studied and characterized by a structural and quantitative analysis of the ovary. Adult females were collected in Sierra de Macha (Totoral, Córdoba, Argentina) between the years 2005-2006. During the phase of recrudesence gonadal (June to March), three values maximum were determined, the first one was observed in June as a result of the first oviposition of the subadults (individual with external adult characteristics but vestigial Bursa of Fabricius presence), the remaining values were registered one in September and the other one in January, corresponding that of the mature females. The ovaric regression is initiated with the hatching, and the resting stage between April and May, in the most of the birds. Two types of atresia were identified: a) the non bursting type, with no rupture of the follicular wall, which includes lipoidal (primordial follicles) and lipoglandular atresia, (previtelogenic follicles and small vitelogenic follicle), of them were observed during the whole reproductive cycle ; and b) the bursting atresia, with rupture of the follicular wall (vitelogenic follicles $>800 \mu \mathrm{m}$ ) only was observed during the gonadal regression. The abundance of females with capacity of reproducing during most of the year and the extensive phase of gonadal recrudescence were characteristics of the $C$. picui reproductive cycle.
\end{abstract}

Keywords: Wild birds, Picui Ground Dove, reproductive cycle, morphohistology,

\section{Introducción}

La reproducción de las aves silvestres ha despertado el interés de muchos investigadores, entre otros, Kern (1972), Lofts et al. (1966), Guraya (1976), Silverin et al. (1986), Williams (1992), Mezquida (2001), empero los trabajos sobre las variaciones estructurales y cuantitativas del ovario durante el ciclo reproductivo de especies aviarias no son abundantes (Erpino 1973, Halse 1985, Gupta y Maití 1986, Guraya 1989a, Ribeiro et al. 1991, 1995, Bulfon y Bee de Speroni 2001, 2003).

Los Colúmbidos por su abundancia y adaptabilidad a diversos hábitats, representan un grupo interesante para el estudio de la relación del medio ambiente con aspectos reproductivos en particular si consideramos el ovario, órgano de compleja estructura con numerosos folículos en diferentes estadios de diferenciación, desarrollo y de involución. Es conocido que, varias especies de palomas están en condiciones de oviponer durante la mayor parte del año e investigadores como Lofts et al. (1966), Frithz et al. (1976), Bucher (1976), Bucher et al. (1977), interpretan que este largo período de ovipostura resulta de ciertos factores determinantes tales como la domesticación y la cantidad de alimento disponible.

La torcacita común Columbina picui (Temminck, 1813) es una de las especies de menor tamaño entre los Colúmbidos y con una amplia distribución en el territorio de la República Argentina. En esta especie han sido realizados estudios sobre dinámica poblacional y distribución geográfica (Nores 1996, Narosky y Yzurieta 2003) y dicromatismo sexual (Mahler y Kempenaers 2002), mientras que son poco conocidos los diferentes aspectos morfológicos del ovario.

En base a estos antecedentes, en el presente trabajo se analiza las características estructurales y cuantitativas del ovario de C. $p i$ cui durante el ciclo reproductivo, a fin de aportar conocimientos básicos a la biología reproductiva de esta especie ampliamente distribuida en la República Argentina.

\section{Material y métodos}

Se capturaron con redes de niebla un total de ochenta y cuatro hembras adultas de Columbina Picus (Temminck, 1813) en la localidad de Macha, Departamento Totoral, Provincia de Córdoba, República Argentina, (6408'27”W, 30³4’02”S) durante los ańos 2005-2006. En el laboratorio, los especimenes fueron anestesiados, pesados y perfundidos intracardíacamente con una solución de Formol al 4\% en una relación de $200-250 \mathrm{~mL}$ por kilogramo de peso y luego disecados. La Bursa de Fabricius se examinó mediante la observación con un microscopio estereoscópico (3X) y la ausencia de la misma fue utilizada como indicador del estado adulto (Wight 1959). Se consideraron 
hembras subadultas, aquellos ejemplares con plumaje de adultos, ovario recrudescente, oviducto no desarrollado y con vestigios de Bursa de Fabricius. El ovario y oviducto se removieron e inmediatamente se pesaron separadamente en una balanza de precisión $(0,1 \mathrm{mg})$; se postfijaron en Formol tamponado a $\mathrm{pH}$ 7,0 , durante 48 horas y posteriormente se procesaron de acuerdo a la técnica de inclusión en parafina. Los cortes seriados de $4 \mu \mathrm{m}$ de espesor se colorearon con Hematoxilina-Eosina y Tricrómico de Mallory (Romeis, 1928).

La caracterización y clasificación de los folículos ováricos en desarrollo (FD), se realizó en base al diámetro y las características histológicas del núcleo, ovoplasma y pared folicular (células foliculares y envolturas tecales), como Ovocitos primordiales (OP), folículos previtelogénicos (FPV), folículos vitelogénicos blancos (FVB), folículos vitelogénicos amarillos (FVA), folículos preovulatorios (FPOV) y folículos postovulatorios (FPO). Se consideraron como folículos atrésicos (FA) aquellos que exhiben notorias alteraciones en el ovoplasma y envolturas foliculares y se categorizaron de acuerdo al criterio de Bulfon y Bee de Speroni (2001; 2003).

El diámetro de los folículos se determino utilizando el programa de digitalización de imágenes Axion Vision 3.0 Carl Zeiss.

Para el análisis cuantitativo del ciclo reproductivo se seleccionaron durante todos los meses 4 ovarios al azar; los FD, FPO y FA, mayores de $3 \mathrm{~mm}$ se contaron bajo estereomicroscopio, mientras que el registro numérico de los folículos menores de dicho diámetro se realizó con un microscopio óptico. A fin de evitar una doble valoración de los mismos se consideró un intervalo de 80 secciones histológicas. Se calcularon los valores promedios y la desviación estándar de los pesos gonadales y los porcentajes de los FD, FPO y FA. Los diferentes estadios del ciclo reproductivo se determinaron teniendo en cuenta el peso del ovario y la distribución y cantidad de FD y FA. Las secciones histológicas fueron observadas y fotografiadas en un microscopio con cámara y película 100 ASA.

\section{Resultados}

\section{Aparato genital femenino de Columbina picui}

El aparato reproductor es asimétrico, está constituido por el ovario izquierdo que representa la gónada funcional y un largo y plegado oviducto ubicado del mismo lado. El ovario está unido a la cavidad abdominal por los ligamentos mesováricos e irrigado por la arteria ovárica, la que penetra a través del tallo folicular ramificándose en cada uno de los folículos. Las venas que recogen la sangre de la gónada constituyen dos troncos venosos, uno anterior y otro posterior los que desembocan en la vena cava posterior.

\section{Características histológicas del ovario}

El examen de las secciones histológicas del ovario coloreadas con Hematoxilina-Eosina, revela un revestimiento superficial constituido por células simples y cúbicas con núcleos redondos $\mathrm{u}$ ovales muy basófilos y dos zonas bien definidas: una periférica o corteza y otra más profunda que corresponde a la médula. En la corteza se localizan los folículos ováricos en diferentes etapas de desarrollo, los postovulatorios, atrésicos y el tejido intersticial; el abundante tejido conectivo constituye el estroma cortical (Fig. 1a). La corteza superficial es más fibrosa y compacta y forma la túnica albugínea. La médula se ubica por debajo de la corteza y representa el estroma medular con numerosas células fusiformes y fibras colágenas. El tejido conectivo medular es más denso en las proximidades de la corteza y laxo hacia el interior por la presencia de una gran cantidad de espacios lacunares, nervios y grandes vasos sanguíneos.

En el ovario se distinguen los siguientes tipos foliculares:

1) Ovocitos Primordiales (OP). Se disponen en forma de cordones sobre el estroma cortical ovárico. Están revestidos por una capa simple de células granulosas y las tecas foliculares aún no se visualizan en estas estructuras ovocitarias. Se distingue en el citosol un notorio cuerpo vitelino o de Balbiani, con numerosas vacuolas a su alrededor, mientras que, en el interior del núcleo se observan los cromosomas en diplotene con configuración Lumpbrush (Fig. 1b). Entre los folículos ováricos, los OP presentan el porcentaje más alto en todos los meses del ciclo reproductivo, registrándose un pico máximo en agosto $(83,24 \%)$ y un mínimo en el mes de julio (50\%) (Fig. 4).

2) Folículos en desarrollo (FD). Durante la diferenciación de los OP a FD numerosas modificaciones estructurales afectan al ovocito, las células foliculares y el tejido conjuntivo circundante, siendo la adquisición de la pared folicular uno de los procesos más evidentes. Así, la capa simple de células foliculares por sucesivas mitosis constituye un epitelio estratificado que, junto a la lámina basal, las envolturas tecales interna y externa forman la pared folicular.

A medida que avanza el desarrollo folicular, la membrana plasmática de las células foliculares presentan numerosas prolongaciones que se relacionan estrechamente con las vellosidades de la capa perivitelina del ovocito constituyendo la zona radiada.

Con la Tinción Tricrómico de Mallory, en las envolturas tecales pueden identificarse numerosos fibroblastos, fibrocitos, fibras colágenas, nervios, vasos sanguíneos y espacios lacunares, diferenciándose una teca interna con numerosos tipos celulares y una externa más colagenizada y gruesa. De acuerdo al grado de desarrollo que presentan estos folículos se diferencian en:

a) Folículos previtelogénicos (FPV). El diámetro de los FPV oscila entre $110 \mu \mathrm{m}$ y $700 \mu \mathrm{m}$. Las células de la granulosa constituyen un epitelio columnar alto y pseudoestratificado y se insinúa la formación de la zona radiada. Entre las envolturas tecales se localizan grupos de 4 a 5 células de aspecto glandular. Los porcentajes ponderados de los FPV, son máximos (21\%) en el mes de diciembre y mínimos $(5,8 \%)$ en enero (Fig. 4).

b) Folículos vitelogénicos blancos (FVB). El diámetro de los FVB está comprendido entre los $310 \mu \mathrm{m}$ y $1600 \mu \mathrm{m}$ y su principal característica lo constituye la incorporación de vitelo blanco. En estos folículos la zona radiada es muy notoria mientras que, en el centro del ovoplasma se localizan gran cantidad de vacuolas de aspecto lipídico (Fig. 1c). A lo largo del ciclo reproductivo, los FVB presentan el mayor porcentaje (13,51\%) en el mes de marzo y el mínimo (2,63\%) en febrero (Fig. 4).

c) Folículos vitelogénicos amarillos (FVA). El diámetro de los FVA está comprendido entre $700 \mu \mathrm{m}$ y $4800 \mu \mathrm{m}$. Las observaciones microscópicas de la capa de células foliculares revelan un estrato de células cuboidales, cuyos núcleos y nucleolos basófilos se tiñen fuertemente con Hematoxilina. A medida que estos folículos incrementan de tamaño cambian paulatinamente su coloración, a causa de la incorporación de gránulos de vitelo 
(a)

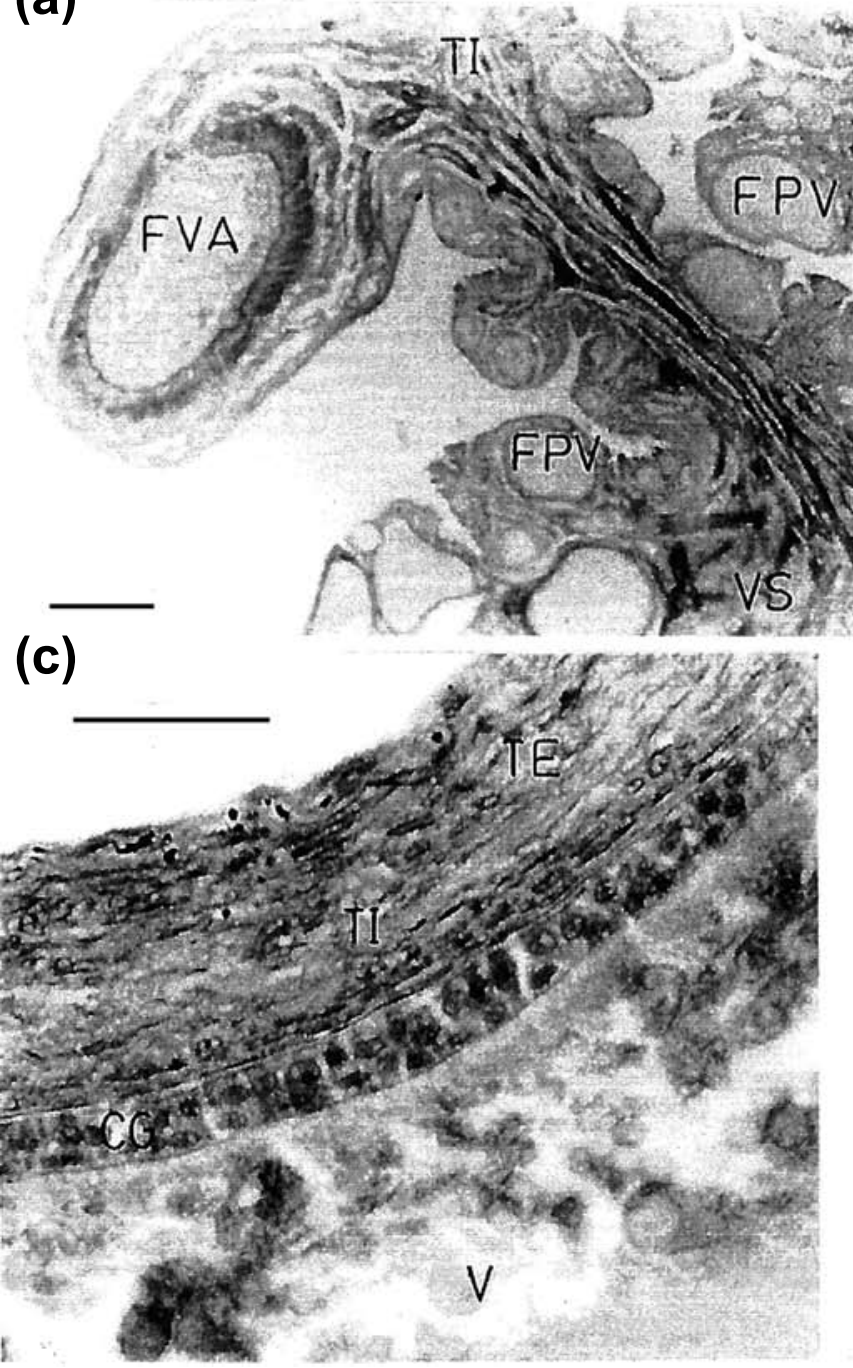

(b)

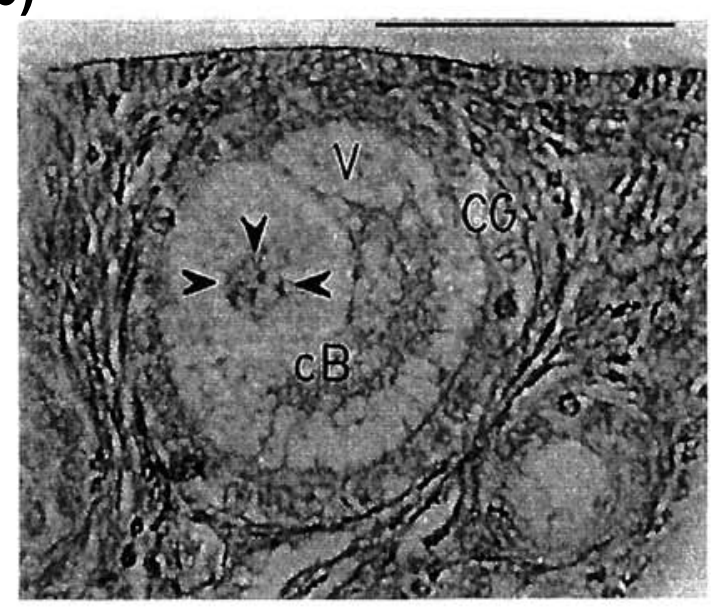

(d)

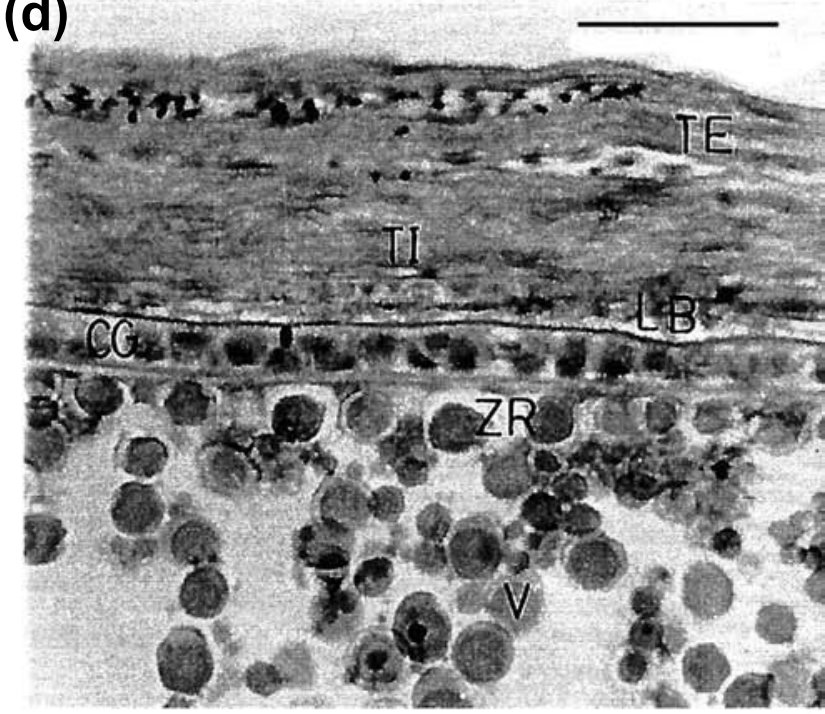

Figura 1. Vista general del ovario de Columbina picui (Fase de recrudescencia gonadal). (a) Se observan numerosos ovocitos primordiales (OP), folículos previtelogénicos (FPV) y un folículo vitelogénico atrésico (FVA) de tipo bursting. Entre los folículos se localiza el tejido intersticial (TI) con abundantes vasos sanguíneos (VS). Coloración: H/E. Barra: $160 \mu \mathrm{m}$. (b) En el núcleo del ovocito primordial se destacan los cromosomas con configuración Lamp brush (cabezas de flechas) y en el citoplasma se localizan pequeñas gotas de vitelo (V) rodeando al cuerpo de Balbiani (cB). Las células de la granulosa (CG) se disponen en una capa simple. Coloración H/E. Barra: $40 \mu \mathrm{m}$. (c) Epitelio folicular de un folículo vitelogénico blanco. Las células granulosas (CG) se estratifican y la teca interna (TI) se diferencia de la teca externa (TE). En el ovoplasma se observan gotas de vitelo (V). Coloración H/E. Barra: $28 \mu \mathrm{m}$. (d) Epitelio folicular de un folículo vitelogénico amarillo. Las células de la granulosa (CG) son cuboidales y están separadas de la teca interna (TI) por una notoria lámina basal (LB). Se destaca la zona radiada (ZR) y numerosos gránulos de vitelo (V) en el ovoplasma. Teca externa (TE). Coloración H/E. Barra: $28 \mu m$.

amarillo (Fig. 1d). En consideración a su tamaño se identifica un ordenamiento o dominancia morfológica de los FVA, el más grande representa al F1 y así sucesivamente F2, F3 y F4. A partir del F4 estos folículos son más pequeños y homogéneos en su diámetro. Los FVA se visualizan durante todo el año con un porcentaje máximo $(6,10 \%)$ calculado en el mes de junio (Fig. 4). Los FVA de aproximadamente $4500-5000 \mu \mathrm{m}$ de diámetro exhiben un color amarillo anaranjado intenso y una notable vascularidad. En la región medial de los mismos se destaca el estigma, una zona clara y poco irrigada o sitio de dehiscencia de las paredes foliculares durante la ovulación, los folículos con estas características corresponden a los folículos preovulatorios.

3) Folículos postovulatorios (FPO). Los diámetros de los FPO varían entre 950 y $4800 \mu \mathrm{m}$. Macroscópicamente tienen el aspecto de un saco plegado, se unen al ovario por un delgado tallo y exhiben una amplia abertura por donde fue expulsado el huevo. El examen microscópico revela en el interior del mismo los restos del epitelio folicular con numerosas células luteales; las tecas aún están bien diferenciadas e irrigadas con abundantes capilares sanguíneos (Fig. 2). En los meses de julio y septiembre se calcula un porcentaje de postovulatorios del 7,32\% y 7,41 $\%$ respectivamente.

4) Folículos atrésicos (FA). La atresia folicular es un proceso degenerativo normal en el ovario de esta especie que afecta a los folículos en distintos estadios de desarrollo. De acuerdo al tamaño y diferenciación de los mismos, como así también a las variaciones estructurales de estos folículos durante el proceso regresivo, se identifican dos tipos de atresia:

a) No bursting, así denominada porque todo el proceso regresivo se realiza en el interior del folículo manteniendo intacta las paredes foliculares, comprende a:

a1) La atresia lipoidal, que es típica de los OP y se caracteriza por la presencia de una gran cantidad de vacuolas de aspecto lipídico que invaden paulatinamente el ovoplasma folicular. 


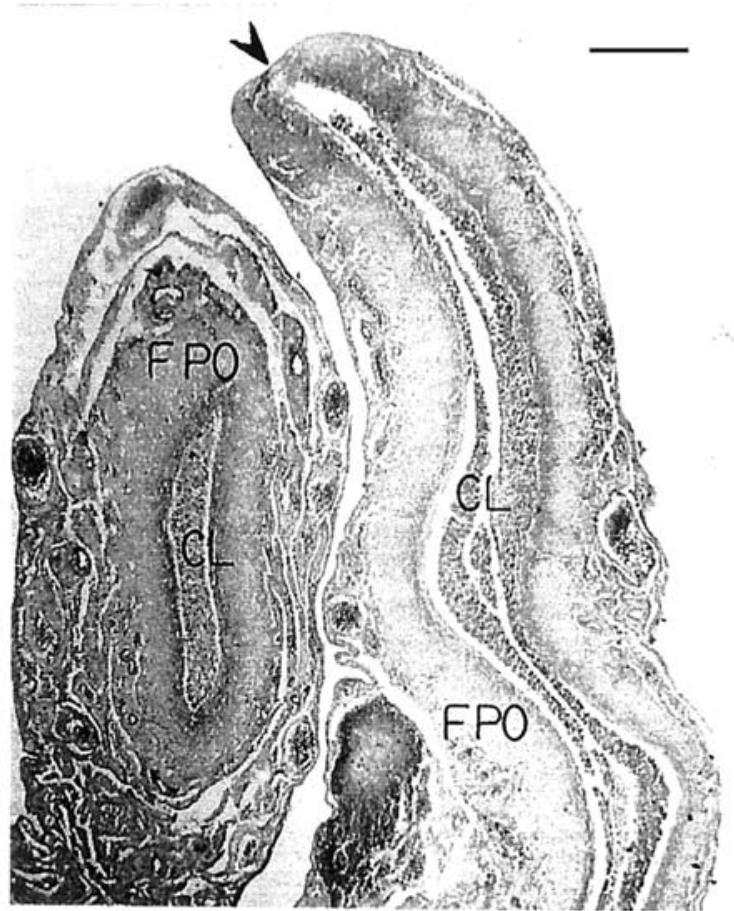

Figura 2 Folículos postovulatorios (FPO) de Columbina picui (Fase de regresión gonadal). Poseen la apariencia de un saco aplanado de tejido conectivo; la cabeza de flecha indica el sitio de apertura del folículo. En el interior de los mismos se localizan restos de epitelio folicular y numerosas células luteales $(\mathrm{CL})$. Coloración $\mathrm{H} / \mathrm{E})$. Barra: $220 \mu \mathrm{m}$.

a2) La atresia lipoglandular comprende a los folículos previtelogénicos y vitelogénicos pequeños $(200 \mu \mathrm{m}$ y $600 \mu \mathrm{m})$ y su nombre hace referencia al aspecto glandular que presenta el folículo atrésico en fases avanzadas de involución (Fig. 3).

b) Atresia bursting o ruptura en la pared folicular de los folículos vitelogénicos mayores a $800 \mu \mathrm{m}$, por este mecanismo se expulsa una gran cantidad de vitelo fuera del folículo regresivo. Los folículos atrésicos se visualizan a lo largo de todo el año, correspondiendo el porcentaje máximo (12\%) a los meses de julio, septiembre y febrero mientras que el porcentaje más bajo (1\%) en abril y mayo (Fig. 4).

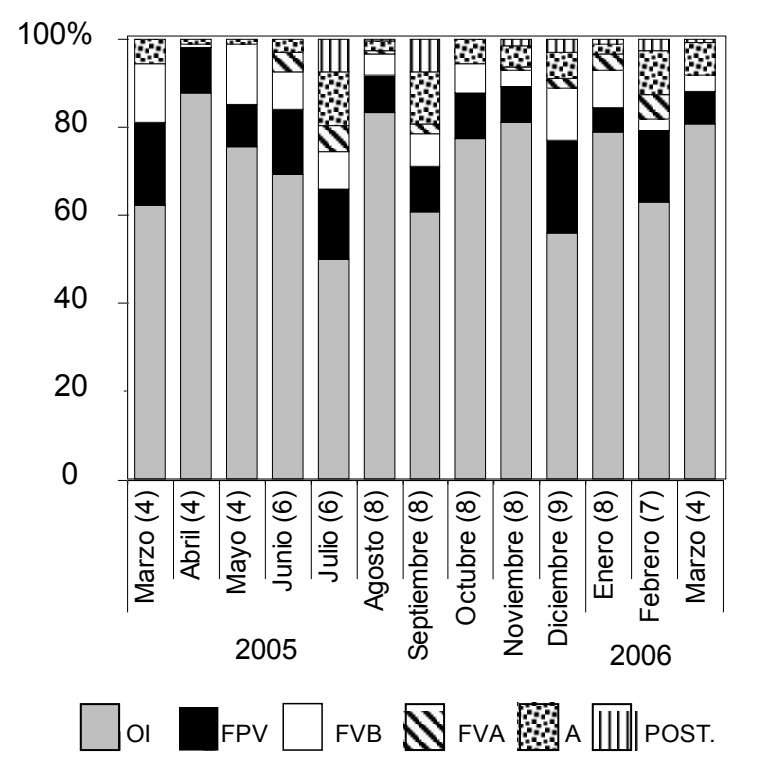

Figura 4. Variaciones porcentuales de los folículos ováricos de Columbina picui durante el ciclo reproductivo 2005 - 2006. Los valores entre paréntesis representan el número de aves.

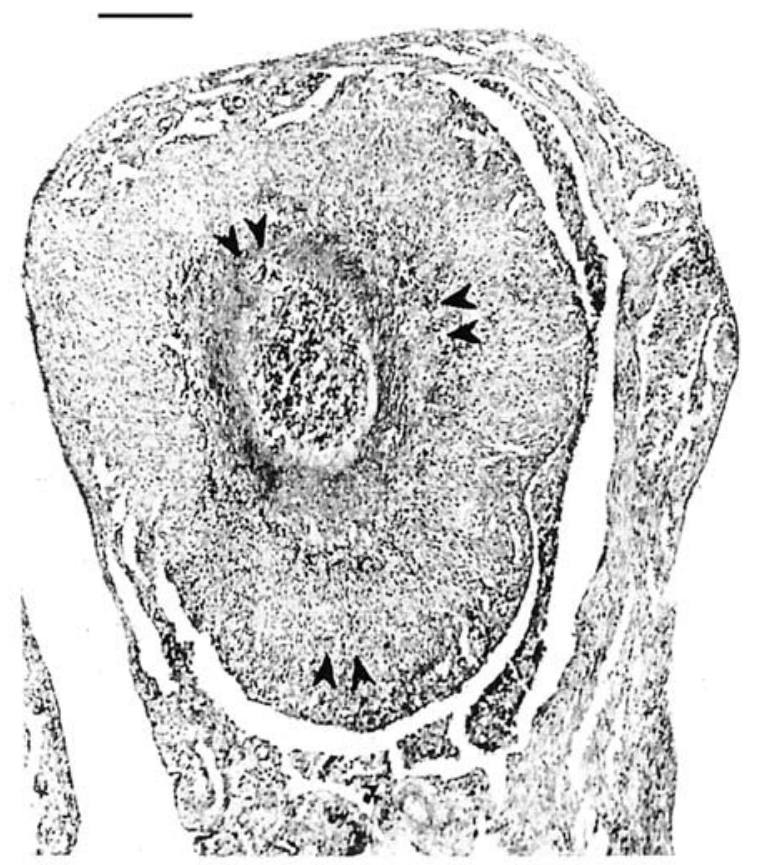

Figura 3. Atresia lipoglandular de un folículo previtelogénico (no bursting) de Columbina picui (Fase de recrudescencia gonadal) en los últimos estadios regresivos. Se señala con las cabezas de flecha una intensa colagenización del epitelio folicular Restos de células granulosas se localizan en el centro del folículo. Coloración T/M. Barra: $187 \mu \mathrm{m}$.

c) Area Intesticial: En el espacio intersticial del ovario se visualiza con la tinción Tricrómico de Mallory numerosas células conectivas, fibras colágenas de color azul intenso y otras de aspecto secretor como así también vasos sanguíneos, todos estos elementos celulares se incrementan notablemente durante la recrudescencia gonadal.

\section{Variaciones de los pesos corporales y gonadales durante el ciclo reproductivo}

El peso corporal de las hembras adultas de C. picui no presenta diferencias significativas durante el ciclo reproductivo anual, calculándose un valor promedio de $54,13 \mathrm{~g} \pm 5,59$. Por el contrario, el peso gonadal experimenta notables variaciones, observándose los mayores valores en junio ( $x=44,70 \mathrm{mg} \pm 10,56)$ luego en septiembre $(x=54,57 \mathrm{mg} \pm 12,69)$ y en enero $(x=116,48 \mathrm{mg} \pm$ $16,05)$, mientras que los menores en los meses de abril ( $x=8,2$ $\mathrm{mg} \pm 1,6)$ y mayo $(\mathrm{x}=7,78 \mathrm{mg} \pm 1,42)$ (Fig.5).

\section{Ciclo Reproductivo}

El ciclo ovárico de C. picui se caracteriza por una prolongada recrudescencia gonadal extendida durante la mayor parte del año con tres picos de ovipostura, uno en junio que corresponde a la de los especímenes subadultos y los otros dos en septiembre y en enero a la de los adultos. La recrudescencia de estos meses se caracteriza por un notable incremento del peso del ovario (Fig. 5) y el desarrollo de FVB y FVA mayor de $4 \mathrm{~mm}$. Posterior a la ovipostura y concomitante con la incubación de los huevos se inicia la regresión ovárica, la ausencia de los grandes FVA conlleva a la disminución del peso de la gónada (Fig.5). Se localizan hasta dos FPO y numerosos FA en este período del ciclo.

La mayoría de las aves examinadas durante los meses de abril y mayo las gónadas presentaban las características estructurales típicas de la fase de reposo, de ese modo se localizan abundantes 


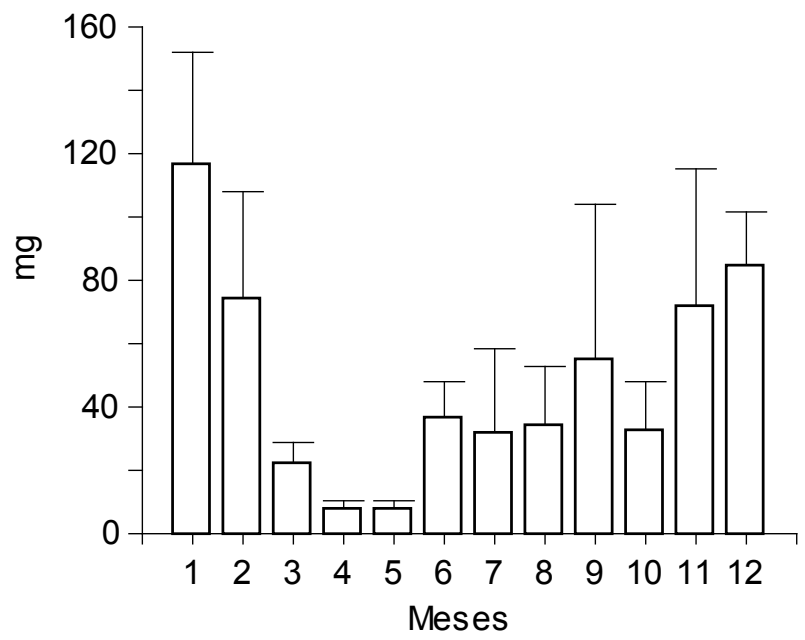

Figura 5. Variaciones mensuales del peso gonadal Columbina picui durante el ciclo reproductivo de marzo 2005 - marzo 2006. A cada mes le corresponde un $n=6$ y las barras representan $(x \pm D S)$.

OP, FPV, FVB y FVA menores de $3 \mathrm{~mm}$ y escasos folículos atrésicos mayores de $3 \mathrm{~mm}$. Los valores mínimos de peso gonadal se ponderan en estos meses (Fig. 5).

\section{Discusión y conclusiones}

El análisis morfohistológico y cuantitativo del ciclo ovárico realizado en el presente trabajo revela que, la población de $C$. picui no exhibe un patrón estacional, por el contrario, la abundancia de hembras con capacidad de reproducirse durante la mayor parte del año constituye una particularidad del modelo reproductivo de este colúmbido. Mientras que el máximo de recrudescencia gonadal de junio se relaciona con la primera ovipostura de las hembras subadultas, los valores de septiembre y enero corresponden al de las aves adultas. Estos valores son el resultado de un activo proceso de desarrollo y diferenciación de los folículos ováricos que conlleva a un notable incremento del peso gonadal y de los valores porcentuales de FVB y FVA mayores de $4 \mathrm{~mm}$.

Durante el período de incubación las hembras inician la regresión ovárica alcanzando, en la mayoría de los casos, el estado de reposo gonadal en los meses de abril y mayo, con una notoria declinación de la actividad reproductiva en esos meses del año.

La ovipostura de hembras subadultas observada en este trabajo no es un evento excepcional de $C$. picui. Este suceso también ha sido descripto en otras especies de Colúmbidos, como en Zenaida auriculata por Bucher et al. (1981) y en Z. macroura, por Wight (1959).

La presencia de numerosos ovocitos primordiales en el ovario de C. picui durante todo el ciclo anual revela que los mismos constituyen la reserva folicular y que un escaso número de folículos son reclutados para iniciar el crecimiento y diferenciación, a través del proceso de foliculogénesis. Mediante este mecanismo los folículos adquieren la pared folicular con notorias modificaciones estructurales, tanto en el epitelio folicular como en las envolturas tecales y túnica albugínea durante la diferenciación folicular.

En el desarrollo y maduración de los folículos ováricos de $C$. Picus las células foliculares también participan en la deposición de gran cantidad de vitelo blanco y amarillo durante la vitelo- génesis, proceso mediante el cual algunos folículos incrementan notoriamente de tamaño. Estos últimos forman una cohorte de folículos amarillos mayores de $4 \mathrm{~mm}$ de la cual surgirán los folículos dominantes que serán ovulados a posteriori.

El ciclo ovulatorio ha sido extensamente estudiado en aves domésticas como en Gallus domesticus por numerosos autores (Gilbert et al. 1983, Etches 1984, Waddington et al. 1985), no obstante, aún no se han dilucidado los mecanismos moleculares implicados en los eventos de jerarquía folicular:reclutamiento, selección y dominancia morfológica y bioquímica de los folículos ováricos dominantes. Cabe acotar que esos sucesos fueron extensamente analizados en diversas especies de mamíferos por Fortune et al. (2004), González Bulnes et al. (2004).

Las células de aspecto luteal entremezcladas con células foliculares de núcleos picnóticos, caracteriza al epitelio folicular de los folículos postovulatorios de C. picui, observaciones que concuerdan con Guraya (1989 b), quien destaca que los FPO de Passer domesticus y $G$. domesticus resultan similares al cuerpo lúteo de los reptiles y mamíferos por la organización morfológica, la presencia de células luteales hipertrofiadas y numerosos vasos sanguíneos.

El proceso de atresia folicular determinado en el ovario de $C$. picui, constituye un mecanismo normal en el mantenimiento del balance entre la proliferación y desarrollo e involución folicular de esta especie.

El máximo valor de atresia lipoidal ponderado durante el reposo gonadal, representaría un factor temprano de selección folicular, mientras que la atresia lipoglandular revelada durante todo el ciclo reproductivo participaría en la formación de la cohorte de los folículos seleccionados. En cuanto al tipo regresivo bursting o por ruptura de la pared folicular detectado sólo a posteriori de la oviposición corresponde a los FVA no dominantes, los que son eliminados del ovario por este proceso involutivo.

Las diferentes clases de atresia folicular que afectan a los folículos ováricos de C. picui también han sido descriptas en el ovario de aves silvestres por otros autores (Halse 1985, Gupta y Maití 1986, Guraya 1989c, Kovács et al. 1992, Bulfon y Bee de Speroni 2001, 2003).

Del presente estudio se infiere que una de las notorias características del ciclo reproductivo de C. picui es la presencia de un gran número de hembras aptas para reproducirse durante la mayor parte del año.

Un aporte similar fue realizado por Bucher et al. (1977, 1981) en $Z$. auriculata, otra especie de amplia distribución en la República Argentina. Esta característica del ciclo reproductivo de los Colúmbidos, según Lofts et al. (1966) es el resultado de distintos factores, entre los que se mencionan: la estimulación que el macho provoca en la hembra, las condiciones favorables del ambiente, una abundante disponibilidad de alimento y además la influencia fotoperiódica.

\section{Agradecimientos}

Los autores desean expresar su agradecimiento a los Ingenieros Agrónomos Oliverio y Alejandro Hayes, por la colaboración en la captura de los ejemplares de C. picui. Al Sr. Juan Pascual Costa del establecimiento "Las Vertientes" de Macha, el cual facilitó el acceso a los campos donde se llevó a cabo el muestreo. A la 
Dra. María de los Angeles Bistoni de la Cátedra de Diversidad Animal II de la Facultad de C.E.F. y N. de la U. N. C., por la lectura crítica del manuscrito.

\section{Literatura citada}

Bucher E. 1976. Bases ecológicas para el control de la paloma torcaza. Rev. Fac. Ci. Ex. Fís. y Nat. Córdoba (Nueva Serie), Biología 1: 141-156.

Bucher E., E. Gómez, I. Di Tada, et al. 1977. Ecología de la reproducción de la paloma Zenaida auriculata .I. Variaciones estacionales en peso corporal, gonadas, reservas de lípidos y muda. Ecosur 4 (7): 47-67.

Bucher E., E. Bonino \& I. Di Tada. 1981. Criterios para determinar edad y sexo en la paloma torcaza (Zenaida auriculata). Neotropica 27 (78): 151-157.

Bulfon M. \& N. Bee de Speroni. 2001. Efecto de la administración exógena de gonadotrofinas (FSH y LH) sobre el ovario de Myiopsitta monachus. (Aves: Psittacidae). Facena 17: 67-77.

Bulfon M. y N. Bee de Speroni. 2003. Atresia folicular en el ovario del Pingüino de Magallanes Spheniscus magellanicus Forster, 1871 (Aves: Spheniscidae). Ararajuba 11(2):189194.

Erpino M. 1973. Histogenesis of atretic ovarian follicles in a seasonally breeding bird. J. Morph.: 239-250.

Etches R.1984. Maturation of ovarian follicles. En: F. J. Cunningham, P. E. Lake \& Hewitt (eds.).Reproductive Biology of Poultry. p 51-73.

Fortune J., G. Rivera \& M. Yang. 2004. Follicular development: the role of the follicular microenvironment in selection of the dominant follicle. An. Reprod. Science: 109-126.

Frithz H., L. McKean \& L. Braithwaite. 1976. Sexual cycles and food of the doves Streptopelia chinensis and S. senegalensis in Australia. The Emu,76 (1): 15-24.

Gilbert A., M. Perry, D. Waddington, et al. 1983. Role of atresia in establishing the follicular hierarchy in the ovary of the domestic hen Gallus domesticus. J. Reprod. Fert.69: 221-228.

González Bulnes A., C. Souza \& B. Campbell. 2004. Systemic and intraovarian effects of dominant follicles on ovine follicular growth. An. Reprod. Science: 107-119.

Gupta S. \& B. Maití. 1986. Study of atresia in the ovary during the annual reproductive cycle of the pied myna. J. Morph. 190 (3): 285-296.

Guraya S. 1976. Morphological and histochemical observations on follicular atresia and interstitial glands tissue in the columbid ovary. Gen. Comp. Endocrinol. 30: 534-538.

Guraya S. 1989a. Follicle wall, p 116 -146. En: W. Burggren, et al. (eds.). Zoophysiology. 24: p $116-146$

Guraya S. 1989b. Postovulatory follicles. En: W. Burggrenet al. (eds.). Zoophysiology. 24: 174-197
Guraya S. 1989c. Follicular atresia. En: W. Burggren et al. (eds.). Zoophysiology. 24: 201-270

Halse S. 1985. Gonadal cycles and levels of luteinizing hormone in wild Spur - winged geese, Plectropterus gambensis. J.Zool., Lond. (A) 205: 335-355.

Kern M. 1972. Seasonal changes in the reproductive system of the female White crowned sparrow, Zonotrichia leucophrys gambelli, in captivity and in the field. I. The ovary. Z.Zellforsch. Mikrosk. Anat. 126: 297-319.

Kovács J., V. Forgó y P. Péczely. 1992. The fine structure of the follicular cells in growing and atretic ovarian follicles of the domestic goose. Cell.Tiss. Res. 267: 561-569.

Lofts B., R. Murton \& N. Westwood. 1966. Gonadal cycles and the evolution of breeding seasons in British Columbiae. J. Zool., Lond. 150: 249-272.

Mahler B. \& B. Kempenaers. 2002. Objective assessment of sexual plumaje dicrhomatism in the picui dove. Condor 104: 203-254.

Mezquida E. 2001. La reproducción de algunas especies de Dendrocolaptidae y Furnaridae en el desierto del Monte Central, República Argentina. Hornero 16 (1): 23-30.

Narosky T. \& D. Yzurieta. 2003. Guía para la identificación de las aves de Argentina y Uruguay. Edicion de Oro. Vazquez Mazzini Editores Editores, Buenos Aires. 348 p.

Nores M. 1996. Avifauna de la provincia de Córdoba. En: I. E. Di Tada y E. H. Bucher, (eds). Biodiversidad de la Provincia de Córdoba. Fauna. Vol.1. Universidad Nacional de Río Cuarto. República Argentina. 373 p.

Ribeiro M., M. Oliveira Teles \& S. Maruch. 1991. Aspectos morfológicos do ovário da rolinha Columbina talpacoti (Temminck,1811), Columbidae, Columbiforme. Rev. Bras. Ciên. Morfol. 8 (2) jul. /dez.

Ribeiro M., M. Oliveira Teles \& S. Maruch. 1995. Morphological aspects of the ovary of Columba livia (Gmelin) (Columbidae, Columbiformes). Revta bras. Zool. 12(1): 151-157.

Romeis B. 1928. La coloración (39 -184). En: Guía Formulario de Técnicas Histológicas. Editorial Labor S.A. Barcelona Madrid - Buenos Aires. 722 p.

Silverin B., P. Viebke \& J. Westin. 1986. Seasonal changes in plasma levels of LH and gonadal steroids in free-living willow tits Parus montanus. Ornis Scand. 17: 230-236.

Waddington D., M. Perry, A. Gilbert \& M. Hardie. 1985. Follicular growth and atresia in the ovaries of hens (Gallus domesticus) with diminished egg productions rates. J.Reprod. Fert. 74:399 -405

Wight H. 1959. A field technique for bursal inspection of Mourning Doves during winter. J. Wildl. Manage. 20: 94-95.

Williams T. 1992. Reproductive endocrinology of Macaroni (Eudyptes chrysolophus) and Gentoo (Pygoscelis papua) Penguins.I. Seasonal changes in plasma levels of gonadal steroids and LH in Breeding adults. Gen. Comp. Endocrinol. 85 : 230-240. 